\title{
INSAT-3DR-rapid scan operations for weather monitoring over India
}

\author{
M. Mohapatra ${ }^{1}$, A. K. Mitra ${ }^{1, *}$, Virendra $\operatorname{Singh}^{1}$, S. K. Mukherjee ${ }^{1}$, \\ Kavita Navria ${ }^{1}$, Vikram Prashar ${ }^{1}$, Ashish Tyagi ${ }^{1}$, Atul Kumar Verma ${ }^{1}$, \\ Sunitha Devi ${ }^{1}$, V. S. Prasad ${ }^{2}$, Mudumba Ramesh ${ }^{3}$ and Raj Kumar ${ }^{4}$ \\ ${ }^{1}$ National Meteorological Satellite Centre, India Meteorological Department, New Delhi 110 003, India \\ ${ }^{2}$ National Centre for Medium Range Weather Forecasting, Noida 201 309, India \\ ${ }^{3}$ Master Control Facility, Indian Space Research Organisation, Hassan 573 201, India \\ ${ }^{4}$ Space Applications Centre, Indian Space Research Organisation, Ahmedabad 380 015, India
}

In order to observe severe weather conditions during cyclones, thunderstorms, etc., IMAGER instruments on-board INSAT3D/3DR have been built with a flexible scanning feature known as 'rapid scan mode'. Using this feature, the number of scan lines over a given coverage region and the number of repetitions of the selected region can be programmed for scanning. Therefore, to understand the physical processes involved in convective clouds associated with severe weather phenomena, rapid scan of INSAT3DR mode is attempted. It has very high temporal resolution of approximately $4 \mathrm{~min}$ and $30 \mathrm{sec}$. The present study will help in better understanding of the physical processes of severe weather phenomena and in nowcasting. It will also help to improve the accuracy in the NWP model forecast through assimilation of radiances and atmospheric motion wind determined using rapid scan mode.

Keywords: Nowcasting, physical processes, rapid scan operations, severe weather conditions, weather monitoring.

INSAT-3DR (INSAT-3D Repeat) is India's advanced dedicated meteorological satellite which was launched on 8 September 2016. It carries four payloads: imager (6 channels), sounder (19 channels), data relay transponder (DRT) and satellite-aided search and rescue (SAS\&R). The imager instruments on-board INSAT-3D and INSAT3DR have been providing meteorological observational image data over the Indian subcontinental region. The scan repetition period for each of these instruments is $30 \mathrm{~min}$. They have been scheduled to scan with $15 \mathrm{~min}$ staggering, so that users can get a full globe update at 15 min intervals. However, they do not provide information about genesis, growth and dissipation of convective clouds which undergo rapid changes during their short lifecycle. Table 1 provides the channel specifications of INSAT-3D/3DR imager ${ }^{1}$.

\footnotetext{
*For correspondence. (e-mail: ashimmitra@gmail.com)
}

To improve forecasting accuracy for the detection of severe weather and deep convection phenomena, a more flexible and powerful observing strategy is needed. International satellite operators and researchers typically define rapid scanning to get images at intervals shorter than the routine scan interval over an area considered as baseline for a given satellite. For example, Meteosat-9 took over the rapid scanning imagery service (RSS) from Meteosat-8 in April 2013. Currently, Meteosat-9 provides RSS, delivering more frequent images every 5 min over Europe only. This assists weather forecasters in one of the most challenging tasks, viz. nowcasting, which involves detecting and monitoring rapidly developing, high-impact weather like thunderstorms or fog, and issuing related warnings up to $12 \mathrm{~h}$ ahead $^{2}$. The Geostationary Operational Environmental Satellite-14 (GOES14) imager was operated by the National Oceanic and Atmospheric Administration (NOAA), USA in an experimental rapid scan 1 min mode during the summers of 2012 and 2013. This scan mode, known as the super rapid scan operation for GOES-R (SRSOR), emulates the hightemporal-resolution sampling of the mesoscale region through scanning by the advanced baseline imager (ABI) on the next-generation GOES-R series ${ }^{3}$. In addition, the Himawari-8 satellite of Japan with advanced Himawari imager (AHI) provides every $2.5 \mathrm{~min}$ rapid scans and every 30-s super rapid scans for selected regions ${ }^{4}$. Sawada et $a l .{ }^{5}$ have shown the assimilation of all-sky infrared radiances from Himawari-8 every 10-min scans and found substantial improvement in the analysis and forecast of isolated and unorganized convective cells.

INSAT-3D/3DR imager payload can be operated in three modes, viz. (i) full frame mode, (ii) programmed normal scan mode and (iii) programmed sector scan mode. Table 2 provides the details of these scan modes. During normal operations, the imager is operated in full frame mode, giving a temporal resolution of $30 \mathrm{~min}$. In order to reduce this temporal resolution, INSAT-3D and INSAT-3DR are being used in a staggered mode. For INSAT-3D, the acquisition cycle starts at 0 and $30 \mathrm{~min}$ 
Table 1. Channel specifications of INSAT-3D/3DR

\begin{tabular}{lclccc}
\hline Channel no. & Channel ID & \multicolumn{1}{c}{ Channel name } & Spectral range $(\mu \mathrm{m})$ & Resolution $(\mathrm{km})$ & Purpose \\
\hline 1 & VIS & Visible & $0.55-0.75$ & 1 & Clouds, surface features \\
2 & SWIR & Shortwave infrared & $1.55-1.70$ & 1 & Snow, ice and water phase in clouds \\
3 & MIR & Medium-wave infrared & $3.7-3.9$ & 4 & Clouds, fog, fire \\
4 & WV & Water vapour & $6.5-7.1$ & 8 & Upper-troposphere moisture \\
5 & TIR1 & Long-wave infrared & $10.3-11.3$ & 4 & Cloud top and surface temperature \\
6 & TIR2 & Split & $11.5-12.5$ & 4 & Lower-troposphere moisture \\
\hline
\end{tabular}

Table 2. Details of scan modes of INSAT3D/3DR

\begin{tabular}{lcc}
\hline Mode of operation & $\begin{array}{c}\text { Time of } \\
\text { coverage (min) }\end{array}$ & Coverage area \\
\hline Full frame mode & 26 & $18^{\circ} \times 18^{\circ}$ \\
Programmed normal scan mode & 23 & $14^{\circ} \times 18^{\circ}$ \\
Programmed sector scan mode & 6 & $4^{\circ} \mathrm{NS}$ and $18^{\circ} \mathrm{EW}$ \\
\hline
\end{tabular}

while for INSAT-3DR the acquisition cycle starts at $15 \mathrm{~min}$ and $45 \mathrm{~min}$, giving an effective temporal resolution of $15 \mathrm{~min}$. The need for operating INSAT-3DR in program mode, i.e. rapid scan mode includes: (i) understanding the science behind weather phenomena, (ii) utilization of the radiances/products in nowcasting and (iii) assimilation of radiances into the NWP models.

The motivation and intent behind carrying out rapid scan from INSAT-3DR imager payload is to understand the physical processes involved in temporal evolution of various weather phenomena as the temporal resolution achieved in the rapid scan is quite high, i.e. approximately $4 \mathrm{~min}$ and $30 \mathrm{sec}$. While achieving this high temporal resolution, the spatial resolution is maintained, i.e. VIS and SWIR scanning are done at $1 \mathrm{~km}$ resolution, TIR1/TIR1/MIR at $4 \mathrm{~km}$ and $\mathrm{WV}$ at $8 \mathrm{~km}$. Therefore, when INSAT-3DR is operated in the rapid scan mode, satellite data are available to forecasters at an interval of every $4 \mathrm{~min}$ and $30 \mathrm{sec}$ in native resolution. With this time range, it is possible to now cast small features such as individual thunderstorms with reasonable accuracy. A forecaster using the latest radar, satellite and observational data would be able to analyse the small-scale features present in a small area such as a city and make an accurate forecast for the following few hours. It is, therefore, a powerful tool in warning the public of hazardous, highimpact weather, including tropical cyclones ${ }^{6,7}$ and thunderstorms which cause flash floods, lightning strikes and destructive winds. The rapid scan operations are even better than that of Doppler weather radars (DWRs) in terms of scanning rate, since the DWR has a temporal resolution of $10 \mathrm{~min}$. Unlike DWR, satellite observations do not suffer from line-of-sight constraint which reduces the effective range to $250 \mathrm{~km}$. Hence, rapid scan satellite acquisition will be a huge boost for nowcasting ${ }^{8}$.

Rapid scanning is important for cyclones as the improved evaluation of cloud character and trends lead to higher confidence in the diagnosis of eye and eyewall characterization, including convection boundaries, centre, diameter, shape, size and evolution of eye and convection on eyewall, eyewall width and its variation. All these provide a better estimate of intensity, location of centre and structural parameters of a tropical cyclone (TC). As the above vital TC parameters are used in the NWP models to initialize or relocate the TC vortex, a more accurate determination of these parameters through rapid scanning will help in improving NWP models and hence short- to medium-range track and intensity forecast. It may be further mentioned that there is no aircraft reconnaissance over the North Indian Ocean (NIO) to provide $\mathrm{TC}$ parameters in the core region. The above observations will help in very short-range forecast and nowcasting of severe weather events like heavy rainfall, wind, storm surge and lightning at the time of landfall.

Further, rapid scan radiances will help determine the best possible atmospheric state using observations and short-range forecasts. The data assimilation is typically a sequential time-stepping procedure in which a previous model forecast is compared with newly received observations. The model state is then updated to reflect the observations and a new forecast is initiated, and so on. During the rapid scan mode, the model state can be updated at a very fast rate. This information can be used to improve the model-based forecast. Finally, reanalysis of weather events with rapid scan data as one of the inputs will help us in understanding the physical processes of the atmosphere. During rapid scan mode in the MMDRPS (multi-mission data reception and processing system) at India Meteorological Department (IMD), New Delhi, all the imageries (IR/VIS/WV/SWIR/MIR) along with the derived products (IMR, OLR, QPE) are generated.

Considering all these, a joint initiative of IMD and Indian Space Research Organisation was taken up for rapid scanning of severe weather events.

\section{Data and methodology}

INSAT-3DR provides program-mode scans during severe weather conditions, while INSAT-3D continues to provide normal mode scan covering full globe. For convenience, the normal mode scan area has been divided into 36 blocks in the north-south $(\mathrm{N}-\mathrm{S})$ direction, such that each block covers $0.5^{\circ}$ in that direction. The number of scan 


\section{RESEARCH ARTICLES}

lines for each block is 40 and the time required to scan each block is 45 sec.

This division makes it convenient to specify the required area of coverage in terms of (i) start block number, (ii) number of blocks to cover and (iii) number of repetitions. Figure 1 shows the flow chart of the rapid scan process.

The effect of varying temporal sampling using brightness temperature (BT) was analysed to examine the utility of rapid scanning, given that 'convection in a thunderstorm or cyclone evolves on timescales shorter than the current INSAT3D operational scan strategies'.

Figure 2 shows three rapid scan schemes followed by IMD and ISRO.

While selecting the area coverage for rapid scan, one has to strike the right balance between extent of coverage and the number of repetitions. To examine its utility, the rapid scan products for a representative thunderstorm and a tropical cyclone case have been analysed in this study.

A potential area of thunderstorm was identified based on synoptic analysis over Karnataka on 15 May 2017. Accordingly, the following were the key features of the rapid scan scheme for INSAT-3DR for analysis of severe thunderstorms over Karnataka on 15 May 2017.

- Chosen scheme: scheme \#2 (7 blocks with 5 repetitions).

- Date: 15 May 2017.

- Time: 06:15, 06:19, 06:23, 06:28, 06:32 UTC.

- Area: Karnataka.

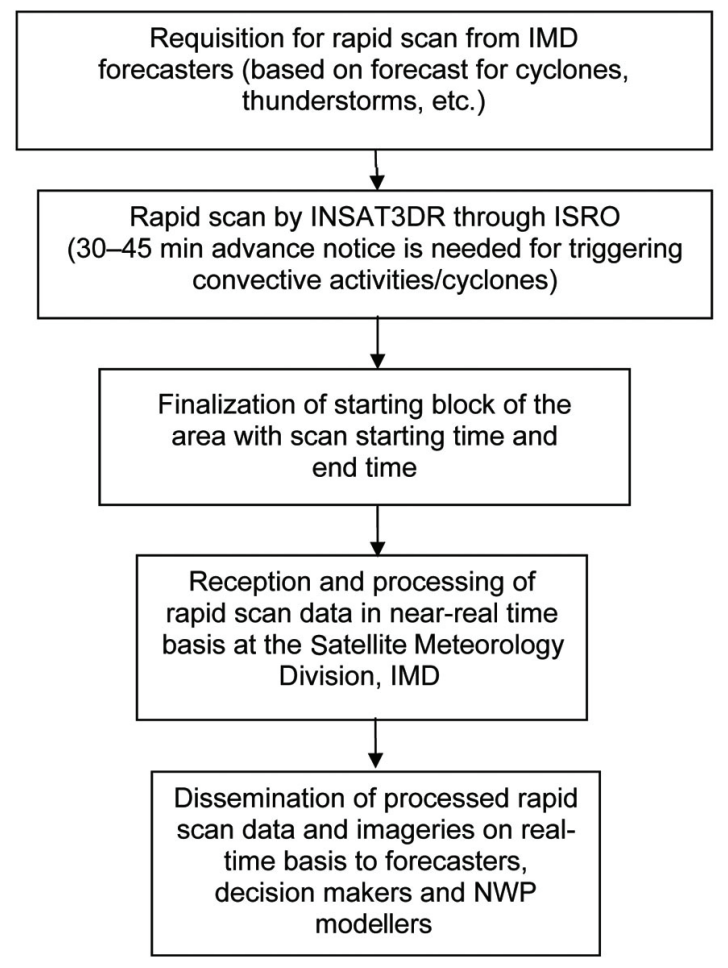

Figure 1. Flow chart of the rapid scan process.
Similarly, the rapid scan of a very severe cyclonic storm Titli over the Bay of Bengal during 8-13 October 2018 was analysed. On the prevailing synoptic conditions and forecast from NWP, request for starting a rapid scan for the cyclone was initiated by IMD to ISRO as follows:

Starting block no. (1-31): 14

Start date (dd-mmm-yyyy): 08-10-2018

Start time (UTC): $00: 00$

End date (dd-mmm-yyyy): 13-10-2018

End time (UTC): 10:15

During movement of the cyclone based on current location and forecasted track, the start location of the rapid scan was also modified. The command for the rapid scan was given by the master control facility (MCF), Hassan, ISRO. Rapid scan can be triggered only after the completion of the ongoing scan (26 min) of INAST-3DR. Hence, 30-45 min advance notice is needed.

\section{Results and discussion}

\section{Thunderstorms}

Figure $3 a$ shows the satellite imageries obtained from rapid scan mode performed over Karnataka region on 15 May 2017 during 0600 to 0630 UTC (area covered: $14^{\circ}-$ $18.5^{\circ} \mathrm{N}, 73^{\circ}-78^{\circ} \mathrm{E}$ ). A time sequence of $4 \mathrm{~min}$ of $10.7 \mu \mathrm{m}$ IR window channel imagery demonstrates the rapid convective development in the form of higher degrees of BT variation with satellite-derived half-hourly INSAT3DR multispectral rainfall (IMR) product between successive images. BT is the temperature of a perfect blackbody (i.e. emissivity =1). Though cloud is not a perfect blackbody, it is assumed so for derivation of BT. The brightness temperature $\left(T_{\mathrm{b}}\right)$ is related to the physical temperature $(T)$ of the object under consideration by the following relation in thermal band.

$$
T_{\mathrm{b}}=\varepsilon T,
$$

In the present case, emissivity $(\varepsilon)$ of the cloud $=1$. Therefore, BT or radiance temperature is the temperature of a blackbody in thermal equilibrium with its surroundings, and depending on the mechanism of radiation it can differ considerably from the physical temperature of a radiating body.

In most areas of northern Karnataka there is an increase in BT of $1-20 \mathrm{~K}$. An increase of more than $20 \mathrm{~K}$ and a decrease of up to $30 \mathrm{~K}$ could also be seen simultaneously. Usually, the cold cloud-top (decrease in BT in successive image) pixels associated with over-shooting cloud tops ${ }^{3}$ are especially important when monitoring rapidly developing systems as they represent the cloudtop emissivity (CTE). The change in CTE with respect to 


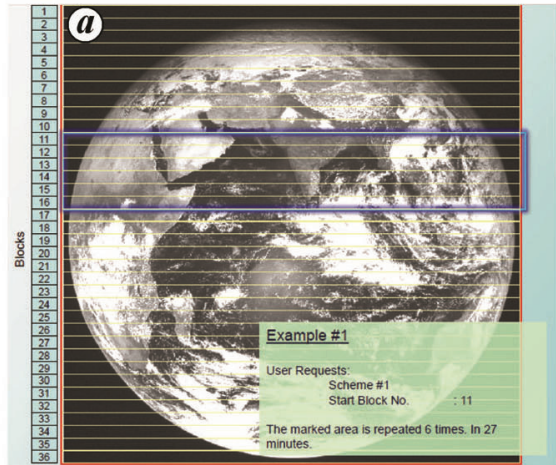

Scheme \#1:

Extent of coverage: 6 blocks ( $3^{\circ}$ coverage in 234 lines) Number of repetitions: 6 Time required: $27 \mathrm{~min}$ (6 blocks with 6 repetitions)

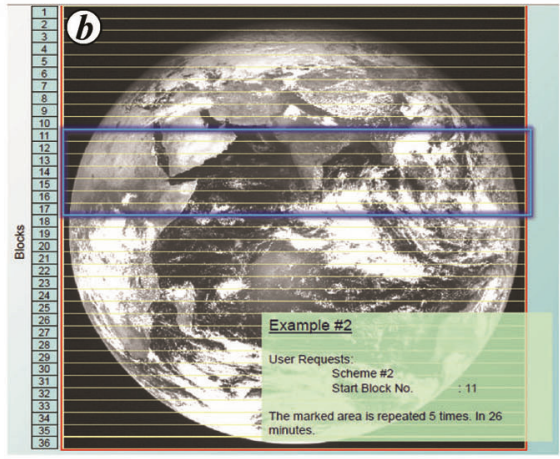

\section{Scheme \#2:}

Extent of coverage: 7 blocks ( $3.5^{\circ}$ coverage in 273 lines) Number of repetitions: 5 Time required: $26.25 \mathrm{~min}$ (7 blocks with 5 repetitions)

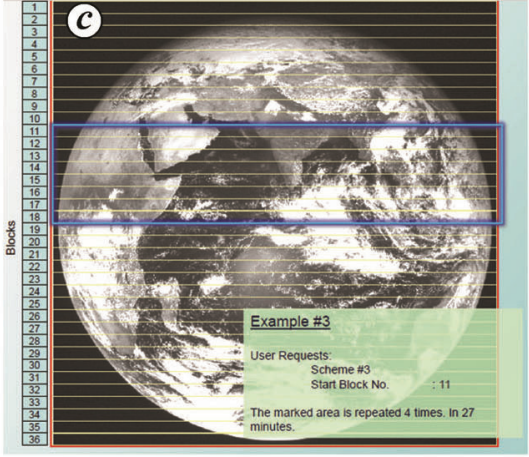

Scheme \#3:

Extent of coverage: 9 blocks ( $4.5^{\circ}$ coverage in 351 lines) Number of repetitions: 4

Time required: $27 \mathrm{~min}$

(9 blocks with 4 repetitions)

Figure $2 \boldsymbol{a}-\boldsymbol{c}$. Rapid scan scheme adopted by India Meteorological Department and Indian Space Research Organisation for the study of severe weather phenomena.

time can be interpreted as the cloud-top cooling rate. In the normal scan mode from INSAT-3D, these rapid changes in temperature could not be properly represented or analysed because scans are available in half-hour intervals (Figure $3 \mathrm{~b}$ ). Whereas these changes are well captured from rapid scans at $4 \mathrm{~min}$ and $30 \mathrm{sec}$ intervals. Similar variation was also noticed in the rainfall product of $\mathrm{IMR}^{9}$. Between 0600 and $0630 \mathrm{UTC}$, it has been observed that IMR increased by $0.05-0.15 \mathrm{~mm}$ in the northern parts of Karnataka, while it decreased by $0.3 \mathrm{~mm}$ in some other parts. This demonstrates that the higher time resolution is especially important when monitoring rapidly developing convective systems and associated weather with heavy spells of rainfall and thunderstorms. The rapid variations on cloud top temperature (CTT) can also be used for monitoring cloud-toground lightning over the Indian region.

Karagiannidis et al. ${ }^{10}$ analysed GOES(R) rapid scan CTT with cloud-to-ground lightning data and showed that a CTT of about $-20^{\circ} \mathrm{C}$ is required for onset of lightning activities. A rapid drop of CTT by about $11^{\circ} \mathrm{C}$ on $5 \mathrm{~min}$ average is observed a few minutes before or during lightning initiation. Maximum lightning occurs with minimum CTT in the cell. A temperature increase of $3.5^{\circ} \mathrm{C}$ can result in end of lightning activity. This is also associated with the time evolution of the horizontal extent of the cell. Once the horizontal area of the cell stops increasing, the lightning activities are expected to stop.

\section{Very severe cyclonic storm Titli}

Under the influence of a cyclonic circulation over North Andaman Sea and adjoining southeast Bay of Bengal (BoB), a low pressure area (LPA) formed over southeast $\mathrm{BoB}$ and the adjoining North Andaman Sea at 0300 UTC of 7 October 2018 (Regional Specialized Meteorological Center (RSMC), New Delhi) ${ }^{11}$. It concentrated into a depression and lay centred at 0300 UTC on 8 October 2018 over east-central $\mathrm{BoB}$, near $14.0^{\circ} \mathrm{N}$ lat and $88.8^{\circ} \mathrm{E}$ long. By 1800 UTC on 8 October 2018, it intensified into a deep depression (DD) over east-central BoB near $14.5^{\circ} \mathrm{N}$ lat and $87.6^{\circ} \mathrm{E}$ long. DD intensified into a cyclonic storm (CS) Titli and lay centred at 0600 UTC on 9 October 2018 over west-central $\mathrm{BoB}$ near $14.8^{\circ} \mathrm{N}$ lat and $86.7^{\circ} \mathrm{E}$ long. The CS moved north-northwestwards and intensified into a severe cyclonic storm (SCS) and lay centred at 0000 UTC on 10 October 2018 over west-central BoB near $16.0^{\circ} \mathrm{N}$ lat and $85.8^{\circ} \mathrm{E}$ long. The SCS further intensified into a very severe cyclonic storm (VSCS) and lay centred at 0600 UTC on 10 October 2018 over westcentral BoB near $16.8^{\circ} \mathrm{N}$ lat and $85.6^{\circ} \mathrm{E}$ long. The VSCS Titli crossed north Andhra Pradesh (AP) - South Odisha coasts, near $18.8^{\circ} \mathrm{N}$ lat and $84.5^{\circ} \mathrm{E}$ long (near Palasa, Srikakulam district, AP) to the southwest of Gopalpur, Odisha. After landfall, the VSCS over south Odisha moved further northwestwards and weakened into an SCS that lay centred at 0600 UTC on 11 October 2018 over south Odisha near $19.3^{\circ} \mathrm{N}$ lat and $83.8^{\circ} \mathrm{E}$ long. The SCS further weakened into a CS and lay centred at $1500 \mathrm{UTC}$ on 11 October 2018 over south Odisha near $20.1^{\circ} \mathrm{N}$ lat and $84.0^{\circ} \mathrm{E}$ long. It further weakened into a DD by 1800 UTC on 11 October 2018 over south Odisha near $20.1^{\circ} \mathrm{N}$ lat and $84.2^{\circ} \mathrm{E}$ long. The DD moved east-northeastwards and weakened into a depression that lay centred at 0900 UTC on 12 October 2018 over Odisha. It further weakened into a well-marked LPA at 0000 UTC on 13 October 2018 over Gangetic West Bengal ${ }^{11}$. Figure 4 shows the track of VSCS Titli.

The most important information obtained from the INSAT-3DR rapid scan mode includes more number of 

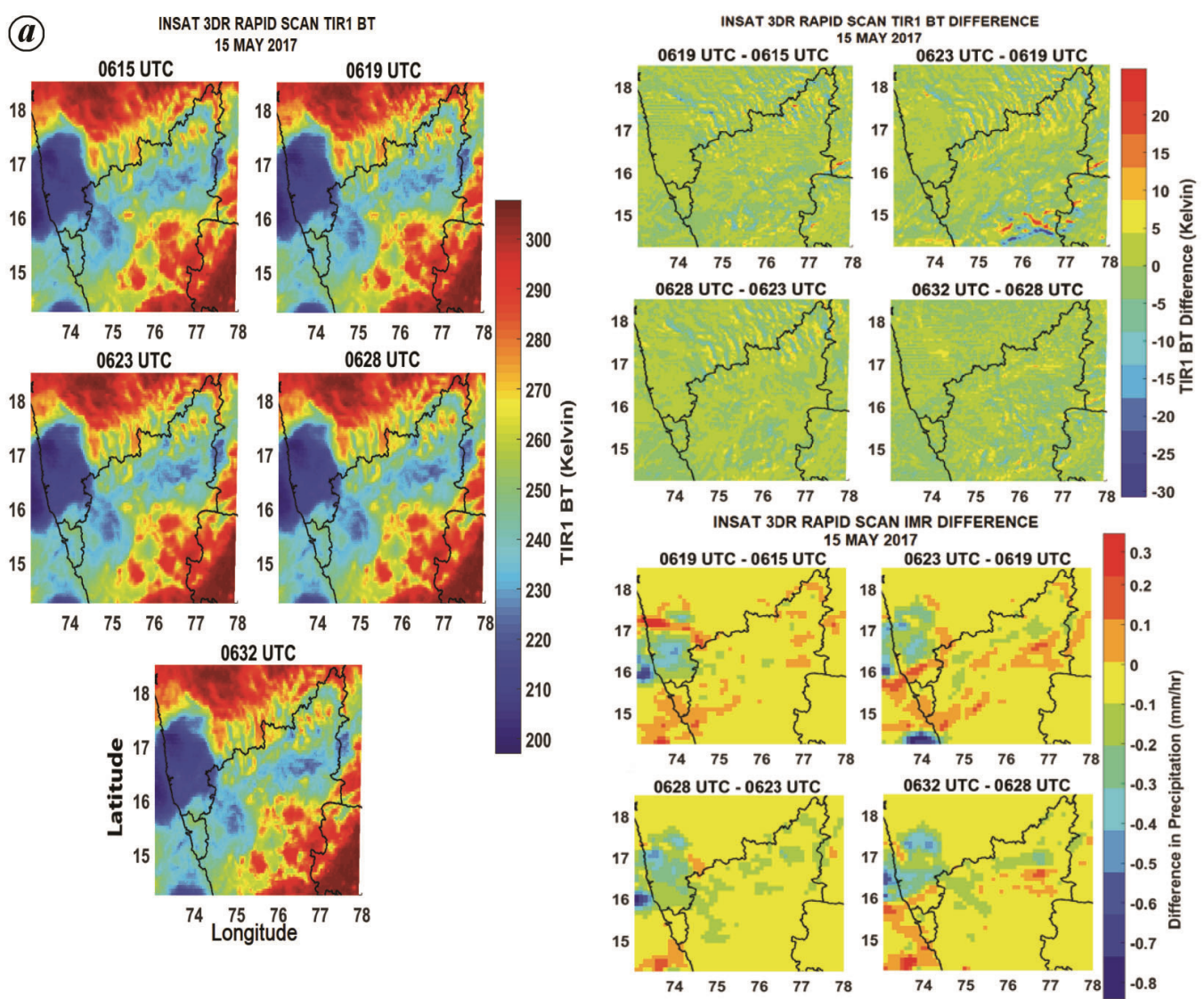

(b) INSAT 3D TIR1 BT 0600 UTC
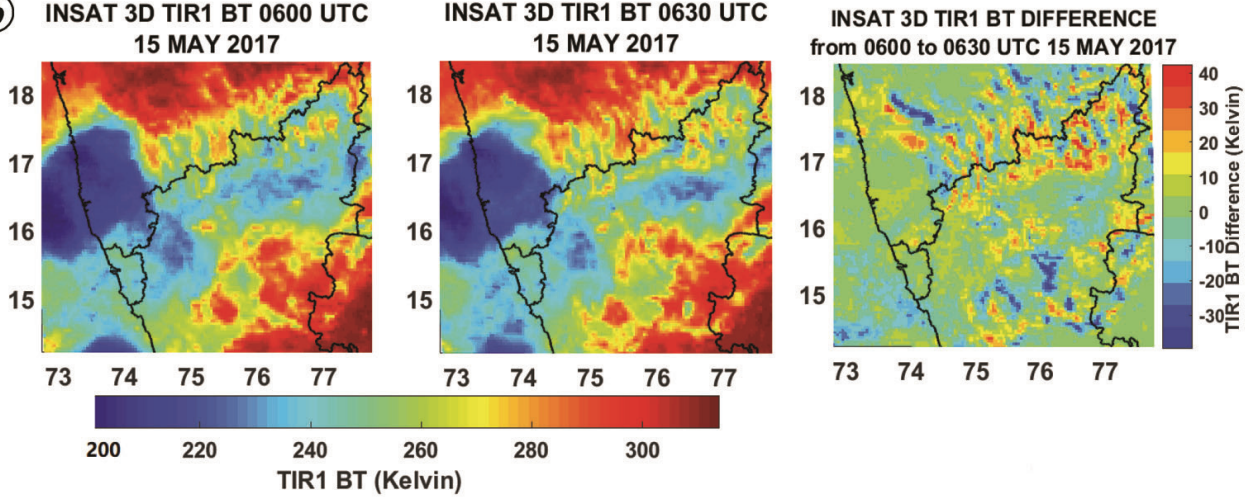

INSAT 3D IMR 0600 UTC

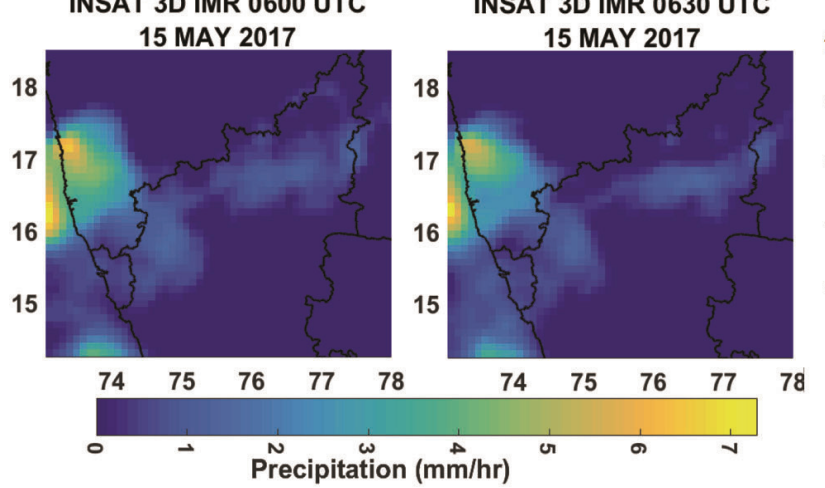

INSAT 3D IMR DIFFERENCE

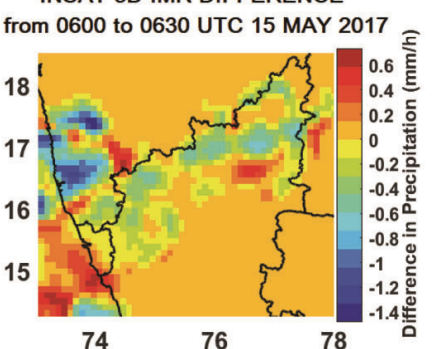

Figure 3. $\boldsymbol{a}$, Rapid scan mode over Karnataka on 15 May 2017 from 0600 to 0632UTC. $\boldsymbol{b}$, Differences of brightness temperature and INSAT3DR multispectral rainfall for INSAT-3D normal scan mode over Karnataka on 15 May 2017 during 0600 to 0630 UTC. 


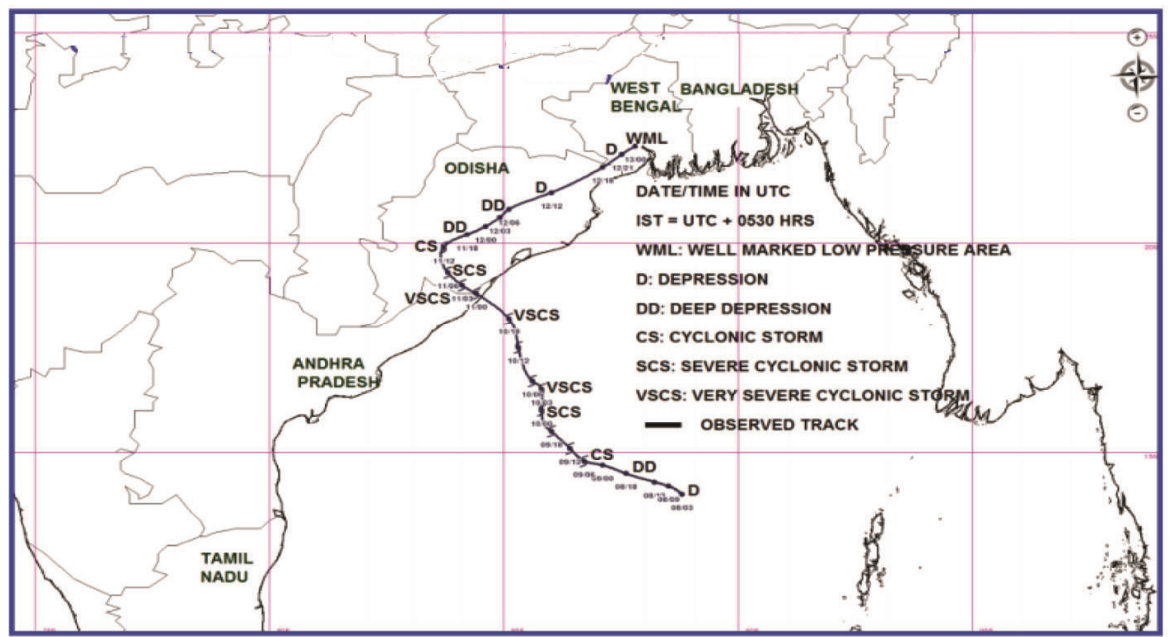

Figure 4. Observed track of VSCS Titli over the Bay of Bengal (8-13 October 2018).
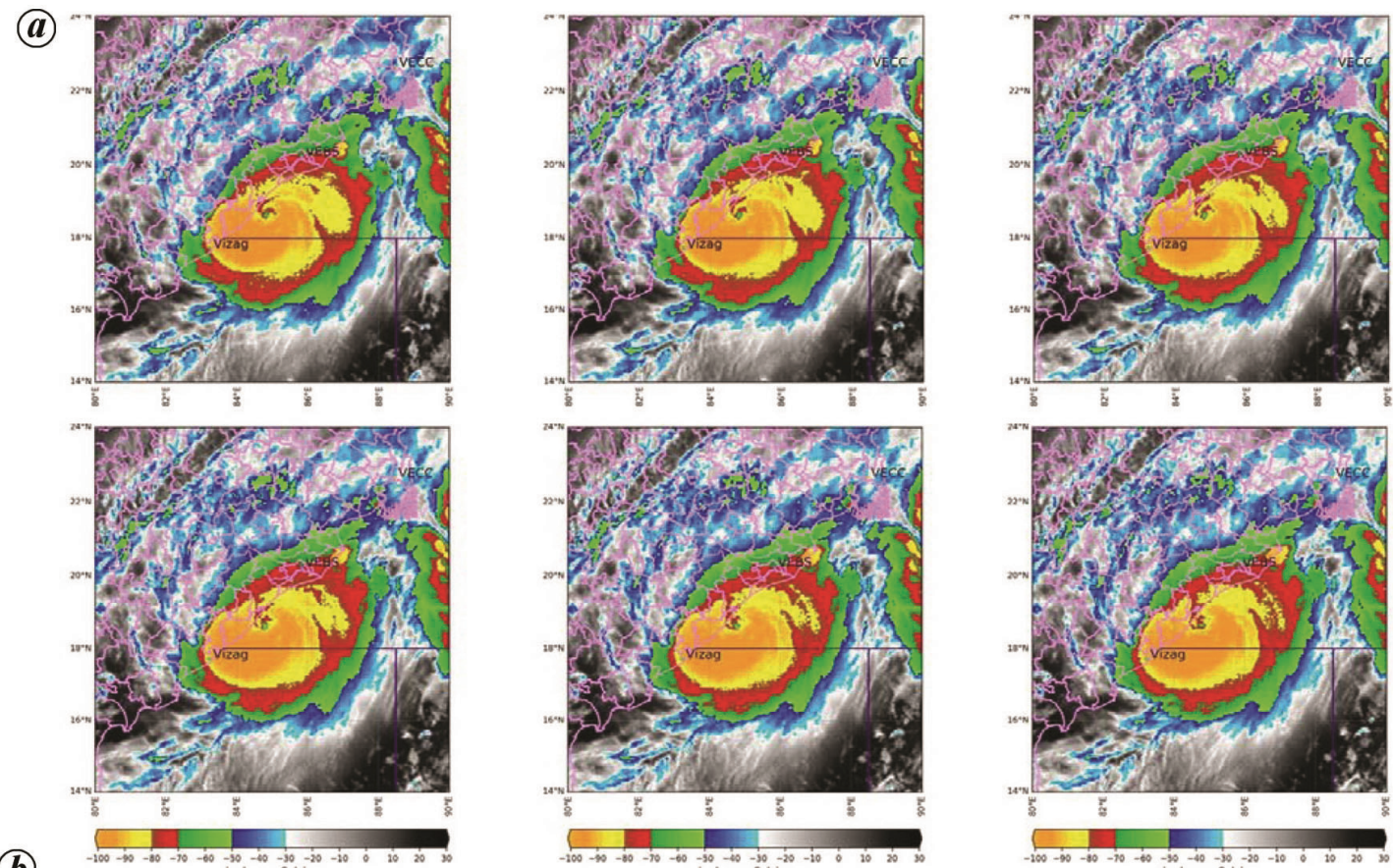

(b)

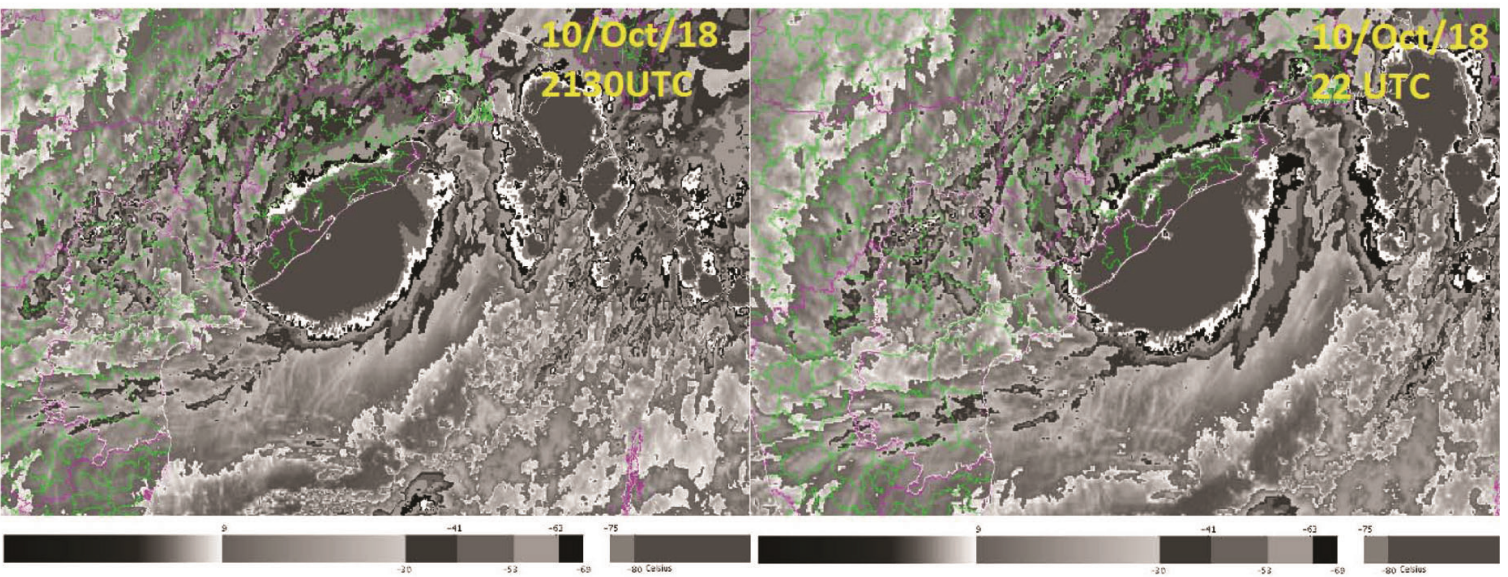

Figure 5. $\boldsymbol{a}$, Rapid scan images for TIR1 temperature from 2115 to 2206 UTC of 10 October 2018. $\boldsymbol{b}$, Normal scan of TIR 1 from 2130 to 2200 UTC on 10 October 2018. 
(a)
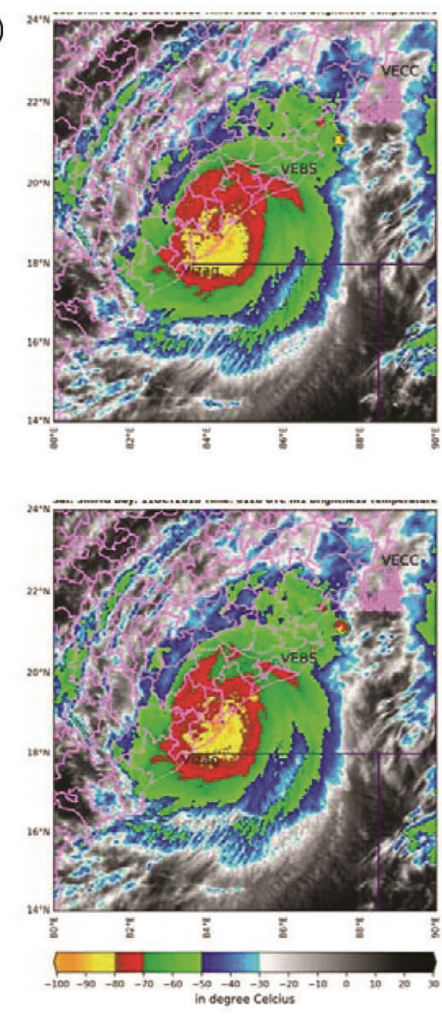
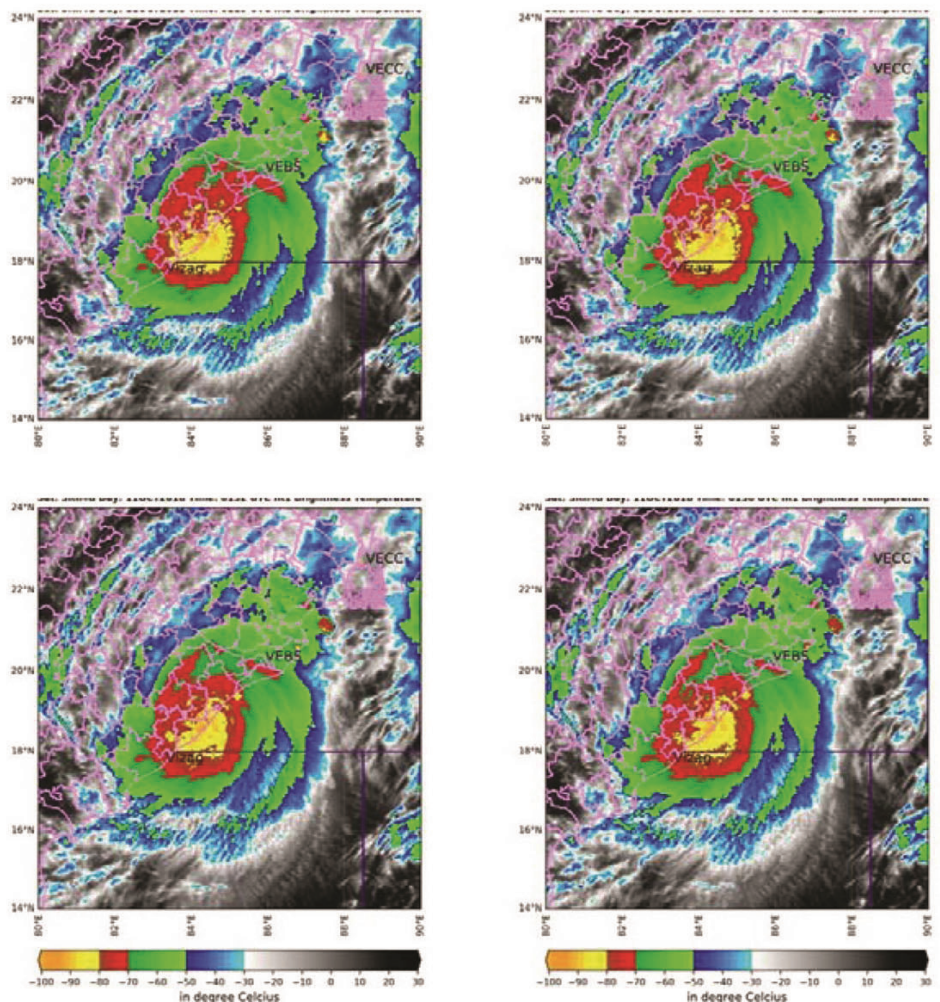

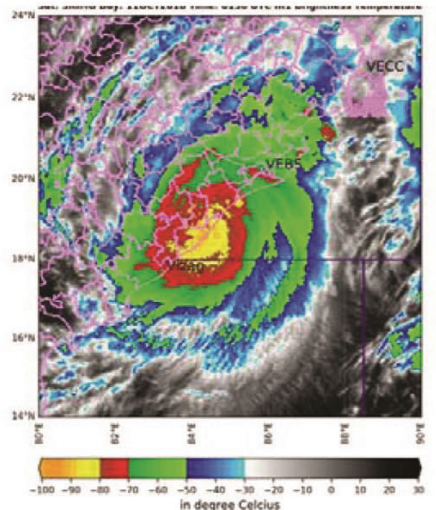

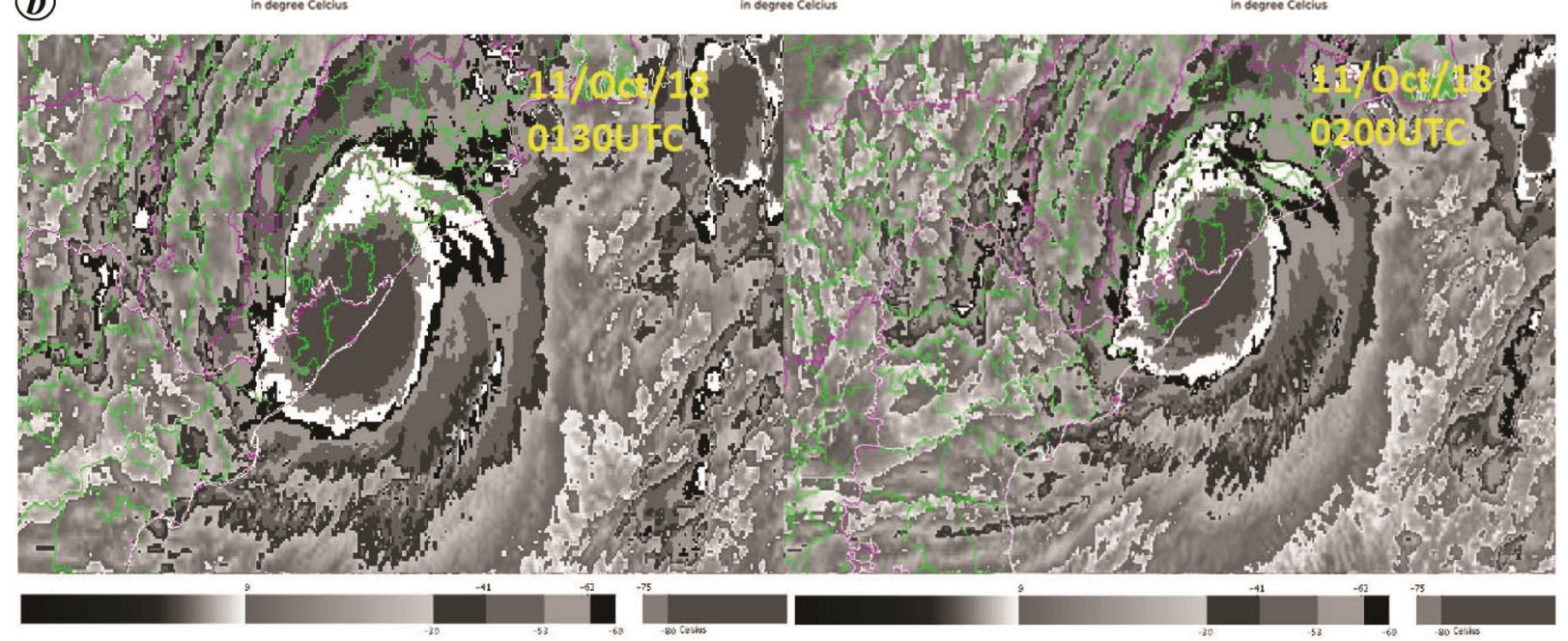

Figure 6. $\boldsymbol{a}$, Rapid scan images for TIR 1 temperature from 0145 to 0206 UTC on 11 October 2018. $\boldsymbol{b}$, Normal scan of TIR1 from 0130 UTC to 0200 UTC 11 October 2018.

cyclone images at shorter scan intervals of $4 \mathrm{~min}$ (approx.), relative to the operational normal scan mode of $30 \mathrm{~min}$ full disk over the Indian region. The 4 min satellite scan image data could aid in the recognition of weakening or intensifying trends associated with the texture of clouds in the cyclone. It also helps in nowcasting and to assess the variation of internal structure in terms of eye and eye-wall characterization, associated convection and precipitation. The early clue could be detected in terms of rapid warming and cooling in the 4 min IR imagery. It is especially important to forecasters at night in the absence of visible imagery. Figures 5 and 6 demonstrate one such event of strengthening and weakening of VSCS Titli respectively. The INSAT-3DR rapid scan of IR imageries of VSCS Titli at 4 min intervals on 10 October 2018 (strengthening) and 11 October 2018 (weakening) were collected from both rapid scan and normal modes. Since coverage location varied each day following the movement of VSCS Titli, each afternoon its expected coordinates (latitude/longitude) for the following day were communicated by the National Weather Forecasting Center to satellite operators for subsequent data collection at SATMET Division of IMD. It can be seen from Figure $5 a$, that on 10 October 2018 , the 'eye' of the VSCS is 
clearly visible (green colour) with little warmer temperature around $-70^{\circ} \mathrm{C}$ to $-60^{\circ} \mathrm{C}$, surrounded by the band of very cold temperature (yellow colour) of around $-100^{\circ} \mathrm{C}$ in the rapid scan mode. In the normal scan mode (Figure $5 \mathrm{~b}$ ), there are only two sets of passes in the $30 \mathrm{~min}$ interval and the ranges of temperature do not vary significantly in the eye and its outer zone. The temperature of the eye is $-68^{\circ} \mathrm{C}$ to $-75^{\circ} \mathrm{C}$, surrounded by cold temperature of $-80^{\circ} \mathrm{C}$. During this time period, i.e. on 10 October 2018, Titli intensified from SCS to VSCS over westcentral BoB. Also, it crossed near $18.8^{\circ} \mathrm{N}$ lat and $84.5^{\circ} \mathrm{E}$ long (near Palasa, Srikakulam district, AP) to the southwest of Gopalpur on 11 October 2018 early morning. The improved evaluation of cloud character and trends in the rapid scan mode led to greater confidence in the diagnosis of eye and eyewall characterization, including convection boundaries, centre, diameter, shape, size and evolution of the eye and convection on eyewall, eyewall width and its variation. Such evolution becomes less evident between longer time intervals of the normal scan mode, making it difficult to interpret important trends on characterization. Subsequently, on 11 October 2018 after landfall, the weakening phases of the VSCS Titli were well demarcated by the colour of IR temperature ranges obtained through rapid scans. Significant weakening trends due to lack of texture in the eye-wall clouds were noticed in the temperature ranges of the rapid scan mode (Figure $6 a$ and $b$ ). It includes detection of rapid warming of clouds in the temperature range of $-80^{\circ} \mathrm{C}$ to $-50^{\circ} \mathrm{C}$ away from the centre of the cyclone. In the normal scan mode, it varied from $-60^{\circ} \mathrm{C}$ to $-30^{\circ} \mathrm{C}$. Hence minute details about the associated convection through the rapid scan mode help in detecting the anticipated distribution of convection and expected squall/gale (winds) and associated rainfall. The time lapse between observations of texture change in the images and intensity change varied from one TC to another and also within the lifecycle period of a TC depending upon internal dynamics interactions (like cloud scaling) between eye, eye wall and spiral bands as well as environmental forces. However, the intensity of TC depends more on the first two interactions which can be captured well through rapid scanning. The lead time thus can vary from a few hours to about $12 \mathrm{~h}$. The fast-updating, seamless animations of 4 min imagery provides the forecaster with enhanced lead time and confidence for areas of ongoing and subsequent intensity of cyclones in a very short time which is not possible when viewing only the 30 min imagery available from INSAT$3 \mathrm{D} / 3 \mathrm{DR}$. It is proposed to utilize the lightning data into the future studies. There are no ground-based lightning detection systems in India for the cases considered in this study. However, recently, the Ministry of Earth Sciences (MoES), Government of India has come up with a lightning detection network in collaboration with the Indian Air Force. It can be utilized in future studies. It may be mentioned here that there is no on-board lightning detection system in INSAT-3D or INSAT-3DR similar to GOES $^{12}$.

\section{Conclusion}

The INSAT-3DR rapid scan demonstrates that shorter intervals are needed to properly observe rapidly evolving convection and other short-lived cloud and small-scale features in order to improve nowcasting capabilities. With program mode schedule, the acquisition of $4 \mathrm{~min}$ of rapid scan from INSAT-3DR satellite provides a unique opportunity to observe many weather phenomena at high temporal resolution, including, but not limited to, clouds, convection and cyclones over the Indian region. The animated loops of rapid scan imageries will certainly help the operational forecasters to monitor the evolving atmospheric state. The rapid scan radiances would be valuable to the mesoscale data assimilation scheme and high-resolution NWP modelling, and could be assimilated in forecast models or used to validate model outputs. With the availability of satellite, lightning and radar data and their combination at a very high temporal resolution, a forecaster has a more complete and continuous view of severe weather phenomena such as thunderstorms and cyclones. There is also scope to derive the atmospheric motion vector ${ }^{13}$ and precipitation estimates ${ }^{14}$ from the rapid scan mode for direct use in NWP modelling as well as predicting severe weather events. Langland ${ }^{15}$ considering the rapid scan winds received from GOES(R) for cyclone Katrina in 2005 over north Atlantic Ocean and showed that the animation of wind derived by rapid scan mode in the NWP model improved the track forecast accuracy by $12 \%$ for the lead period of $84-120 \mathrm{~h}$. Li et $a l .{ }^{16}$ analysed the rapid scan winds in three hurricanes over the north Atlantic Ocean using HWRF model and found that assimilation of these winds consistently improved the model by track and size forecast and had a mixed impact on intensity forecast. Thus, there is vast scope to utilize the rapid scan data of INSAT-3DR for understating and predicting severe weather events over the Indian region. Further, the quick output from rapid scan data every 4 min will need quick interpretation. Hence, we need to develop automated processes like auto-animation for visual interpretation, automated DVORAK technique for determination of $\mathrm{T}$. numbers and hence intensity, automated assessment of its impact in terms of rainfall and other severe weather.

1. IMD, A technical report 'INSAT-3D Data Products Catalog', India Meteorological Department, New Delhi, January 2014.

2. EUMETSAT, Meteosat-9 takes over rapid scanning service, 9 April 2013; http://www.eumetsat.int/Home/Main/News/Press Releases $/ 831419 ? 1=$ en 


\section{RESEARCH ARTICLES}

3. Schmit, T. J. et al., Geostationary operational environmental satellite (GOES)-14 super rapid scan operations to prepare for GOES-R. J. Appl. Remote Sensing, 2013, 7(1), 073462.

4. Bessho, K. et al., An introduction to Himawari-8/9-Japan's new-generation geostationary meteorological satellites. J. Meteorol. Soc. Jpn., 2016, 94(2), 151-183; https://doi.org/10.2151/ jmsj.2016-009.

5. Sawada, Y., Okamoto, K., Kunii, M. and Miyoshi, T., Assimilating every-10-minute Himawari-8 infrared radiances to improve convective predictability. J. Geophys. Res.: Atmos., 2019, 124 2546-2561; https://doi.org/10.1029/2018JD029643.

6. Dvorak, V., Tropical cyclone intensity analysis and forecasting from satellite imagery. Mon. Weather Rev., 1975, 103(5), 420 430

7. Dvorak, V., Tropical cyclone intensity analysis using satellite data. NOAA Tech. Rep. 1984, 11, 45; NOAA/NESDIS, Washington, DC, USA, 1984, p. 45.

8. Ribeiro, B. Z., Machado, L. A. T., Huamán, Ch. J. H., Biscaro, T S., Freitas, E. D., Goodman, S. J. and Mozer, K. W., An evaluation of the GOES-16 rapid scan for nowcasting in Southeastern Brazil: analysis of a severe hailstorm case. Weather Forecast., 2019, 34(6)

9. Gairola, R. M, Mishra, A., Prakash, S. and Mahesh, C., Development of INSAT multi-spectral rainfall algorithm (IMSRA) for monitoring rainfall events over India using Kalpana-IR and TRMM-precipitation radar observations. Scientific Report, SAC/EPSA/AOSG/INSAT/SR-39/2010, 2010, p. 22.

10. Karagiannidis, A., Lagouvardos, K., Kotroni, V. and Mazarakis, N., Investigation of isolated thunderstorms lightning activity over eastern Mediterranean using Meteosat rapid scan infrared imagery. Int. J. Remote Sensing, 2016, 37(20), 5001-5020; doi:10.1080/ 01431161.2016.12260000.

11. RSMC, Report on cyclonic disturbances over North Indian Ocean during 2018. No. ESSO/IMD/CWD Report No-01 (2019)/09. India
Meteorological Department, New Delhi and World Meteorological Organization, 2019

12. Goodman, S. J., Blakeslee, R. J., Koshak, W. J., Mach, D., Bailey, J. and Buechler, D. L., The GOES-R geostationary lightning Mapper (GLM). Atmos. Res., 2013, 125-126, 34-49.

13. Velden, C. et al., Recent innovations in deriving tropospheric winds from meteorological satellites. Bull. Am. Meteorol. Soc., 2005, 86, 205-223.

14. Gallucci, D. et al., Convective initiation proxies for nowcasting precipitation severity using the MSG-SEVIRI rapid scan. Remote Sensing, 2020, 12, 2562.

15. Langland, R. H., Velden, C., Pauley, P. M. and Berger, H., Impact of satellite-derived rapid-scan wind observations on numerical model forecasts of Hurricane Katrina. Mon. Weather Rev., 2009, 137, 1615-1622; https://doi.org/10.1175/2008MWR2627.1.

16. Li, J., Li, J., Velden, C., Wang, P., Schmit, T. J. and Sippel, J., Impact of rapid-scan-based dynamical information from GOES-16 on HWRF hurricane forecasts. J. Geophys. Res.: Atmos., 2020, 125, e2019JD031647; https://doi.org/10.1029/2019JD031647.

ACKNOWLEDGEMENTS. We thank the entire teams of SACIMDPS, Master Control Facility and U.R. Rao Satellite Centre, ISRO, Ahmedabad for technical support specially while carrying out rapid scan at IMDPS, New Delhi. We also thank C. M. Kishtwal, Deb Jyoti Dhar, P. Tapliyal, Nitesh Kaushik, Kamlesh Patel, Satish Kulkarni, N. Basavaraj, L. J. Vijaya Kumar, Gomathi Saratha and Imtiaz Ahmed for technical inputs and support, and the Chairman, ISRO, Secretary, MoES and NWFC Division of IMD.

Received 26 September 2020; revised accepted 4 December 2020

doi: $10.18520 / \mathrm{cs} / \mathrm{v} 120 / \mathrm{i} 6 / 1026-1034$ 